\title{
VICENTE ALCALÁ GALIANO, LOS FRUTOS CIVILES Y LA INFLUENCIA SMITHIANA
}

JUAN HERNÁNDEZ ANDREU

El libro de ensayos de Vicente Alcala Galiano Sobre la Economía Política y los Impuestos, recientemente editado con un estudio preliminar de José Manuel Vallés Garrido ', me da pie a escribir esta nota por las razones que expondré seguidamente. $\mathrm{La}$ influencia smithiana en Vicente Alcala Galiano era ya bien conocida antes de que se publicara este libro 2 . Por otro lado, opino que la genuina reforma tributaria ilustrada radicó en el establecimiento de los frutos $c i$ viles por Floridablanca.

Veamos este último punto. La historiografia hacendística sobre los tributos españoles de la segunda mitad del siglo XVIII y principios del xIX ha considerado que la «Contribución Unica» del marqués de la Ensenada y los sucesivos intentos de establecer la Única Contribución hasta las reformas tributarias de las Cortes de Cádiz y de Martín de Garay marcaron la linea reformista y modernizadora del llamado sistema tributario tradicional castellano, basado en la alcabala y otras rentas provinciales, y que con el establecimiento de aquella figura tributaria, semejante al catastro y otros impuestos directos vigentes en la Corona de Aragón, iba a instaurarse un sistema uniforme para toda España, asi como la unidad de Caja.

En esta nota quiero presentar la tesis de que la reforma tributaria ilustrada de aquel periodo descansa en el establecimiento de los frutos civiles por Floridablanca entre 1785 y 1787 y en la defensa de esta nueva contribución que hiciera Vicente Alcalá Galiano pocos meses después del Plan de reforma de Flo-

I V. Alcala Galiano (1992): Sobre la Economia Política y los Impuestos. Segovia, 1781-1788. Edjción y estudio preliminar de José Manuel Valles Garrido, Academia de Artillería de Segovia, Se. govia.

2 J. Hernandez Andreu (1972), pp. 121-183. 
ridablanca contenido en el Decreto de 8 de julio de 1787, que ampliaba el Plan fiscal de 29 de junio de 1785, de la Instrucción provisional de 21 de septiembre y de los reglamentos de 14 y 26 de diciembre de 1785 , conforme al Dictamen que la Comisión de Rentas Provinciales presentó sobre un proyecto que ya habia adelantado el conde de Floridablanca a consecuencia del análisis critico que presentó éste a la reforma fiscal del conde Cabarrús. El Plan de Cabarrús fue publicado en 1783 y el documento crítico a dicha reforma fiscal fue presentado por Floridablanca el 15 de mayo de $1784^{3}$.

El impuesto de frutos civiles fue un impuesto directo que gravaba los arrendamientos de la propiedad con un tipo impositivo del 5 por 100 que exaccionaba las rentas de los hacendados, propietarios, vecinos y forasteros. Se trató de un impuesto directo de producto que contaba con la ventaja de ofrecer una base imponible determinada y fácilmente conocible, que constituyó un precedente institucional a la reforma de 1845 . El nuevo plan fiscal conservaba los impuestos indirectos sobre los consumos y enajenaciones, ventas, comercios e industrias de los demás vecinos que no fuesen propietarios. En la distribución técnica del impuesto, el Plan de Floridablanca fue un sistema en el que predominaron los impuestos indirectos; pero introdujo los frutos civiles, lo cual fue un avance institucional dentro del conjunto de contribuciones tradicionales, como impuesto directo de producto sobre la riqueza tradicional, rústica y urbana, y sobre los rendimientos de capital.

Con fecha de 18 de marzo de 1788, dada en Madrid, Vicente Alcalá Galiano presentó una Memoria ${ }^{4}$ en la que el autor hace referencia al Real Decreto de 6 de diciembre de 1785, que prohibia se levantaran de modo arbitrario «Los precios de los arrendamientos de las tierras», con el fin de evitar que los propietarios percutieran a los colonos los impuestos sobre la renta; prueba de que Floridablanca trazaba su plan de acuerdo a una serie de medidas adoptadas previamente y condicionantes de la eficacia del mismo. Asimismo sigue de cerca el plan fiscal de Floridablanca, haciendo una defensa del mismo fundándose en el pensamiento de Adam Smith y en particular exponiendo, una a

${ }^{3}$ Conde de Floridablanca: Instrucción reservada que la Junta de Estado creada formalmente por mi Decreto en este dia, 8 de julio de 1787, deberá observar en todos los puntos y ramos encargados a su conocimiento y examen, en obras originales.. y escritos referentes a su persona, colección hecha e ilustrada por don Antonio Ferrer del Rio, Biblioteca de Autores Españoles, ed. Atlas LIX, Madrid, 1952. Conde de Cabarrus: Memoria al rey nuestro señor Carlos III para la extinción de la Deuda Nacional y arreglo de contribuciones en 1783, en las Cartas sobre los obstáculos que la naturaleza, La opinión y las leves oponen a la felicidad pública. Barcelona. Conde de Floridablanca: Dictamen sobre el proyecto de Única Contribución, 15 de mavo de 1785, en Archivo de López Ballesteros, 12/1, Ministerio de Hacienda.

+ Sobre la necesidad y justicia de los tributos, fondos de donde deben sacarse y medios de recaudarlos, Madrid, 18 de marzo de 1788 . Ahora reproducida por Valles Garrido. 
una, las máximas tributarias smithianas contenidas en la riqueza de las Naciones. Asi, refiriéndose a la primera máxima dirá: «Los impuestos que se hagan sobre cualquier especie de los tres fondos que constituyen la renta de la Sociedad, deben extenderse igualmente a todos los individuos del Estado, de manera que ninguno se vea obligado a pagar más que otro consumiendo igual cantidad de rentas. La alcabala, pues, que antes de los nuevos Reglamentos de 1785 se pagaba en los Pueblos por todas las reventas que se hacian dentro de ellos, era un tributo oneroso, perjudicial y contrario a esta verdadera máxima». El apoyo de Vicente Alcalá Galiano al plan fiscal de Floridablanca, fundándose en argumentos de Adam Smith, es explícito; sobre el particular escribi en otro lugar 5 .

Ante los hechos que acabo de exponer, la cuestión que se planteaba era si la coincidencia argumental entre las máximas tributarias de la Riqueza de las Naciones y los Reglamentos reguladores del Plan fiscal de Floridablanca y la imposición de los Frutos Civiles obedecía a una influencia smithiana sobre la reforma fiscal ilustrada a través de Vicente Alcalá Galiano o si las concordancias entre la reforma de Floridablanca y el pensamiento smithiano obedeció a un conocimiento directo del ministro ilustrado de la obra de Smith. Y cabria también la posibilidad de que el Plan de Floridablanca se inspirara en la doctrina de predecesores de Adam Smith y en la obra de Montesquieu bien conocida por los ilustrados españoles que se esforzaban en buscar instituciones fiscales que fueran viables, combinando la filosofia de defensa de los derechos de los individuos, su libertad individual y su aplicación práctica en términos de igualdad de trato fiscal con la ayuda de la aritmética política; y que luego la obra de Adam Smith viniera a corroborar los principios del Plan de Floridablanca. Pues bien, sobre esta cuestión la obra de José Manuel Vallés Garrido ha hecho una gran aportación. Deja claro que Vicente Alcala Galiano no conocia la obra de Smith antes de que se publicara la reforma de Floridablanca e implantaran los frutos civiles en León y Castilla en 1785-1787. También deja claro que Vicente Alcalá Galiano influyó en el plan de Floridablanca en lo referente a la reforma de los impuestos sobre el consumo tomando su memoria presentada en la Real Sociedad Segoviana de Amigos del Pais en lo referente a las modificaciones de los impuestos del consumo de carne y aceite, donde hace gala de notable ilustración con su lógica de aritmética politica aplicada a los tributos y su sentido práctico fiscal. También parece evidente que una vez Alcalá Galiano ha leido a Adam Smith se convierte éste en su autor principal para fundamentar cientificamente sus reflexiones tributarias asi como el conte-

\footnotetext{
'J. Hernández Andreu (1972).
} 
nido de los Reglamentos de 1785-1788 que desarrollaron el plan fiscal de Floridablanca, bajo el ministerio del conde de Lerena en el despacho de Hacien. da. Con ello se evidencia que el reformismo tributario de la jlustración descalificó, con palabras de Floridablanca y de Vicente Alcalá Galiano, la viabilidad de la Única Contribución y apoyó, con el juicio positivo de estos ilustrados, el establecimiento de los frutos civiles y la reforma de las rentas provinciales, como via conducente a una eficaz reforma tributaria a la luz de la Economía politica que sistematizan las máximas tributarias contenidas en la Riqueza de las Naciones. A partir de 1788 Vicente Alcalá Galiano colaboraria en Madrid con el ministro del Despacho de Hacienda, conde de Lerena.

La autoria de la reforma de 1785-1787 es del conde de Floridablanca, que mostré documentalmente en mi trabajo citado. Asimismo en el pensamiento de Floridablanca converge la experiencia tributaria española con el pensamiento ilustrado que se puede observar en su texto: «El establecer de repente una contribución única por lo que se ha declamado en muchos papeles y en las operaciones antiguas, causaria un trastorno general en la monarquia, con riesgo evidente de arruinarla (...). El deseo de establecer los tributos con una justicia tan rigurosa, que quedan cargados con igualdad matemática o aritmética sobre los bienes de los súbditos, y el anhelo de evitar los gastos de empleados y las menudas y gravosas formalidades de las cobranzas, han deslumbrado a los hombres más justificados para trabajar por la formación de esta contribución única; pero tales deseos, que especulativamente son laudables, están sujetos en la práctica a tantas dificultades e inconvenientes, que no se ha podido ni podrá jamás verificar la ejecución” 6 . Sugeria Floridablanca que se reformaran los impuestos indirectos en las provincias de León y Castilla, respetando principios como aque no basta que el tributo se cargue con justicia e igualdad, si no se facilita y endulza su cobranza» 7 . Máxima ésta que indirectamente se refiere a las dos primeras máximas de Adam Smith y de modo directo y completo a la tercera máxima smithiana.

Respecto a la valoración negativa que hace Vallés Garrido de la eficacia de los frutos civiles, discrepo, como es obvio, acerca de este punto de vista. Aunque fuera derogado este impuesto en 1794 no hay que olvidar que estuvo vigente durante nueve años y la Única Contribución no llegó a practicarse nunca. Además la reforma de Floridablanca introdujo un plan que combinaba la reforma de las rentas provinciales con la innovación de un impuesto directo de producto sobre la riqueza tradicional, rústica y urbana, y sobre los rendi-

"Instrucción..., cit., 253.

'Instrucción..., cit., 254. 
mientos de capital. Esta distribución técnica del impuesto fue la orientación que se impondria en la reforma moderna del orden tributario español con Alejandro Mon. La Única Contribución en sustitución de las rentas provinciales era inviable.

Quiero dejar sentado que el plan de Floridablanca era genuinamente critico y radicalmente diferente al plan de Cabarrús. Una diferencia básica era que éste proponia gravar la propiedad y Floridablanca a las utilidades de la propiedad. Otra era que Cabarrús eliminaba las rentas provinciales y el plan de 1785 1787 las reformaba.

Naturalmente que los frutos civiles encontraron oposición entre los propietarios, pero estuvieron vigentes, conforme se habian instaurado, durante un decenio y luego se asignarian a la amortización de los Vales Reales. No olvidemos -el propio Artola habla de la Quiebra del Antiguo Régimen 1779. $1808^{8}$ - que el periodo de Carlos IV fue caótico para la Hacienda pública debido al auge de los gastos extraordinarios del Tesoro público que exigieron arbitrios también extraordinarios y ello supuso que arbitrios ordinarios como los frutos civiles, figura clave de la reforma tributaria ilustrada, devinieran en recursos destinados a satisfacer las necesidades del Crédito público. El resultado fue un desmantelamiento del sistema de Hacienda, que se intensifica durante la guerra de la Independencia, y que trataron de recomponer las Cortes de Cádiz y después Martín de Garay, pero recurriendo de nuevo al paradigma de la contribución única que Floridablanca había descalificado y abandonado.

Es cierto que la distribución técnica del impuesto que aportaban los frutos civiles si lo comparamos con la clasificación de impuestos directos de producto que estableció la reforma de 1845 resultaba todavía muy elemental, pero si lo comparamos con el proyecto de la Única Contribución de la Ensenada considero que la figura tributaria de Floridablanca era una notable innovación, ya que además se combinaba con impuestos indirectos reformados. El propio A]calä Galiano tenia una visión evolutiva del sistema triburario, de modo que a medida que crecen los factores productivos y se diversifican las actividades económicas en una sociedad cobrarán importancia nuevos modos de tributación.

La descalificación que hace Artola de los frutos civiles en el sentido también de que desaparecieron en 1794 no es totalmente precisa ${ }^{9}$. Los rendimientos de los frutos civiles entre 1785 y 1794 estan pendientes de un estudio preci. so, aunque haya indicios de que no fueron lo que cabria esperar; luego se

\footnotetext{
* Artola (1982), p. 321.

9 Artola (1982), p. 335.
} 
asignarian a la amortización de Vales Reales, disponiéndose algunas modificaciones en el tipo impositivo y en los sujetos pasivos, con determinadas exenciones para el estado eclesiástico "10. La reforma de Martín de Garay suprimió los fratos civiles y fueron restablecidos por Luis López Ballesteros, quien no se explicaba la poca producción de esta renta de la Corona hasta entonces; luego debió aumentar su rendimiento. Gonzalo Anes nos dice que la reforma de Garay suprimió los frutos civiles, pero esta afirmación requiere algunas matizaciones. Asi en la memoria de Garay previa al decreto de reforma del Crédito pú. blico se constata la vigencia de la «contribución extraordinaria de frutos civiles extendida a todas las provincias del Reyno, y reducida al 4 y $2 \mathrm{p} \%$ la cantidad de 6 y 4 que se exigia»; se cifra su valor en 6.000 .000 de reales de vellón y se observa que ues de la Pragmatica de 1800 . El Consejo de Castilla propuso la misma reducción conforme con sus Fiscales: los de Hacienda opinaban por la supresion, y el Presidente, y tres Ministros votaron, porque subsistiese el 6 y 4 $\mathrm{p} \%$ también lo juzgó asi la Junta del Crédito público, y por el decreto de 13 de Octubre se aprobó su continuación. Ahora se propone con alteración, pero indicando que deberá cesar o variarse, si se consigue la unidad por el sistema de Hacienda». Los decretos de reforma de Hacienda y del crédito público de Martín de Garay (1817-1818) introdujeron la contribución general cuyo importe total estaba integrado por ala suma que compongan dichas Rentas Provinciales suprimidas que no se conservan, las equivalentes de la Corona de Aragón, la contribución de Paja y utensilios, el subsidio eclesiástico, y el importe de la contribución extraordinaria de frutos civiles que se ha de resarcir al crédito público; añadiéndose las alcabalas o derechos enajenados correspondientes a las primeras, y la cantidad suficiente para cubrir los presupuestos, e igualar las cargas con las obligaciones del Estado" (articulo 23 del Decreto de 30 de mayo de 1817). Por tanto, la reforma de Garay reconocia el impuesto directo de frutos civiles y lo absorbia en la contribución directa general de su plan; ello era consecuencia del paradigma de la Única Contribución de la Ensenada; que la historia iria rectificando; asi, el propio Garay introduciria un nuevo impuesto de producto, el derecho de puertas, que constituyó la mayor innovación de su reforma.

En 1824-1826 los frutos civiles se recuperan como impuestos ordinarios y suponen según Fontana el 2,33 por 100 de todos los ingresos ". Este porcentaje se mantendria, segun las cifras que proporciona Francisco Comin ${ }^{12}$, hasta 1845. Fabián Estapé deja muy claro el protagonismo de esta figura tributaria

\footnotetext{
10 Anes (1974), p. 28-30.

11 Fontana (1973), p. 95.

12 Comin (1988), vol. i, p. 128.
} 
que fue absorbida por el impuesto sobre la propiedad inmobiliaria, cifrando su volumen de ingresos en 14.000 .000 de reales, lo cual suponia el 7,2 por 100 del importe total de la contribución directa sobre el producto liquido de los bienes inmuebles "13. A su vez este impuesto era el mas importante cuantitativamente de la reforma de 1845, suponiendo el 30 por 100 del total de ingresos del Tesoro español conforme a los datos del profesor Comin ${ }^{14}$.

El proyecto de Ley de reforma de 1845 en su artículo 2." establecía la contribución sobre el producto liquido de los bienes inmuebles que refundia las contribuciones de Paja y Utensilios, la de Frutos Civiles, la de Cuarteles, el derecho de sucesiones, la manda pia forzosa, el donativo señalado a las provincias vascongadas y el cupo territorial de la contribución de culto y clero ${ }^{15}$. Asimismo se establecia la Contribución sobre Consumo que abarcaba los derechos de Puertas creado por Martin de Garay, asi como la Contribución industrial que incluia el Subsidio industrial y de Comercio creado por el ministro Luis Lopez Ballesteros ${ }^{16}$.

Aun admitiendo que desde el punto de vista cuantico los resultados de ingresos públicos por la contribución de frutos civiles fue mediocre, no obstante, el establecimiento de dicha figura tributaria supuso una novedad institucional que estaba en la vanguardia del pensamiento tributario que la racionalidad de la Economia politica justificaba, que conocian algunos ilustrados españoles $y$ que corroboraba el pensamiento económico smithiano. A la larga, cosa que no ocurrió con la Única Contribución, los frutos civiles perduraron y fueron un enlace institucional entre los hacendistas ilustrados y los hacendistas espanoles modernos.

\section{BIBLIOGRAFIA}

ANis, G. (1974): «La Contribución de Frutos civiles entre los provectos de reforma tributaria en la España del siglo xvilı,. Hacienda Pública Española, núm. 27.

Ar Tol.A. M. (1982): La Hacienda del Antiguo Régimen. Madrid.

Comin Comix, F. (1988): Hacienda y Economía en la España Contemporánéa, 2 vols., IEF, Madrid.

Estapt, F. (1971): La reforma tributaria de 1845, IEF, Madrid.

Fontaxi, J. (1973): Hacienda y Estado 1823.1833. IEF, Madrid.

"Estapé, 233

it Comin, 151.

"Estape, 240 y 245.

16. Estapé, 14, 16, 245 y 246. 
Hernandez Andret, J. (1978); «Evolución histórica de la contribución directa en España desde 1700 a 1814", Revista de Economia Política, núm. 61, mayo-agosto, 1972, 31.90. Reeditado por ibidem (1978): Historia Económica de España. Lecturas, ed. Uned y Confederación Española de Cajas de Ahorro, Madrid. 121-183.

LASARTE, J. (1976): Economía y Hacienda al final del Antiguo Régimen. Dos Estudios, IEF, Madrid. 